\title{
Genome comparison of two Exiguobacterium strains from high altitude andean lakes with different arsenic resistance: identification and 3D modeling of the Acr3 efflux pump
}

OPEN ACCESS

Edited by:

Partha Basu,

Duquesne University, USA

Reviewed by:

C. French,

University of Edinburgh, UK John W. Moreau

University of Melbourne, Australia

${ }^{*}$ Correspondence:

Adrian G. Turjanski, INQUIMAE-UBA/CONICET, Ciudad Universitaria Pabellón II, Int. Guiraldes

2620, C1428EHA Buenos Aires,

Argentina

adrian@qi.fcen.uba.ar

Specialty section:

This article was submitted to

Microbiological Chemistry and

Geomicrobiology,

a section of the journal

Frontiers in Environmental Science

Received: 22 December 2014

Accepted: 02 July 2015

Published: 22 July 2015

Citation:

Ordoñez OF, Lanzarotti E, Kurth D, Cortez N, Farías ME and Turjanski AG

(2015) Genome comparison of two

Exiguobacterium strains from high

altitude andean lakes with different

arsenic resistance: identification and 3D modeling of the Acr3 efflux pump.

Front. Environ. Sci. 3:50.

doi: 10.3389/fenvs.2015.00050

\section{Omar F. Ordoñez ${ }^{1}$, Esteban Lanzarotti ${ }^{2,3}$, Daniel Kurth ${ }^{1}$, Néstor Cortez ${ }^{4}$, María E. Farías ${ }^{1}$ and Adrian G. Turjanski ${ }^{2,3 *}$ \\ ${ }^{1}$ Laboratorio de Investigaciones Microbiológicas de Lagunas Andinas, Planta Piloto de Procesos Industriales Microbiológicos (PROIMI), CCT-CONICET, Tucumán, Argentina, ${ }^{2}$ Departamento de Química Inorgánica, Analítica y Química Física/INQUIMAE-CONICET, Facultad de Ciencias Exactas y Naturales, Universidad de Buenos Aires, Ciudad Universitaria, Buenos Aires, Argentina, ${ }^{3}$ Departamento de Química Biológica, Facultad de Ciencias Exactas y Naturales, Universidad de Buenos Aires, Ciudad Universitaria, Buenos Aires, Argentina, ${ }^{4}$ Instituto de Biología Molecular y Celular de Rosario (IBR - CONICET), Facultad de Cs. Bioquímicas y Farmacéuticas (Universidad Nacional de Rosario), Rosario, Argentina}

Arsenic exists in natural systems in a variety of chemical forms, including inorganic arsenite (As [III]) and arsenate (As [V]). The majority of living organisms have evolved various mechanisms to avoid occurrence of arsenic inside the cell due to its toxicity. Common core genes include a transcriptional repressor ArsR, an arsenate reductase ArsC, and arsenite efflux pumps ArsB and Acr3. To understand arsenic resistance we have performed arsenic tolerance studies, genomic and bioinformatic analysis of two Exiguobacterium strains, S17 and N139, from the high-altitude Andean Lakes. In these environments high concentrations of arsenic were described in the water due to a natural geochemical phenomenon, therefore, these strains represent an attractive model system for the study of environmental stress and can be readily cultivated. Our experiments show that $\mathrm{S} 17$ has a greater tolerance to arsenite $(10 \mathrm{mM})$ than $\mathrm{N} 139$, but similar growth in arsenate $(150 \mathrm{mM})$. We sequenced the genome of the two Exiguobacterium and identified an acr3 gene in S17 as the only difference between both species regarding known arsenic resistance genes. To further understand the Acr3 we modeled the 3D structure and identified the location of relevant residues of this protein. Our model is in agreement with previous experiments and allowed us to identify a region where a relevant cysteine lies. This Acr3 membrane efflux pump, present only in S17, may explain its increased tolerance to As(III) and is the first Acr3-family protein described in Exiguobacterium genus.

Keywords: arsenic resistance, Exiguobacterium, membrane proteins, sequencing, ACR3 


\section{Introduction}

Arsenic exists in natural systems in a variety of chemical forms, including inorganic arsenite (As [III]) and arsenate (As [V]) and methylated organic forms. Arsenate behaves as a phosphate analog interfering with phosphate uptake and utilization, while arsenite is able to disrupt many enzymatic activities. The majority of living organisms have evolved various mechanisms to avoid occurrence of arsenic inside the cell, although some bacteria are able to use it as chemical energy source or need the metalloid for growth (Stolz and Oremland, 1999; Macy et al., 2000; Silver and Phung, 2005). It has been suggested that a relationship exists between arsenic toxicity and cellular antioxidant systems (Hrimpeng et al., 2006; Pandey et al., 2012).

Genes related to arsenic resistance in bacteria are usually encoded in the so called ars operons. These operons have varied configurations, but the common core genes include a transcriptional repressor ArsR, an arsenate reductase ArsC, and an arsenite efflux pump which extrude this toxic species (Paez-Espino et al., 2009). The pumps belong to two different unrelated families, the ArsB proteins from the Major Facilitator Superfamily, and the Acr3 proteins from the BART superfamily (Mansour et al., 2007). The ArsB proteins are best characterized, and have been shown to extrude both arsenite and antimonite in a mechanism driven either by the electrochemical gradient or by ATP hydrolysis when the ArsA ATPase is present (Rosen et al., 1999). Members of the Acr3 family are found in bacteria, archaea and fungi (Rosen, 1999; Wysocki et al., 2003) and in environmental studies acr3 genes seem to be very widespread among arsenic resistant bacteria, even more than $\operatorname{ars} B$ genes (Achour et al., 2007; Cai et al., 2009). Nevertheless, Acr3 proteins have been functionally characterized only in a few species including Bacillus subtilis, Synechocystis sp., Corynebacterium glutamicum and Saccharomyces cerevisiae (López-Maury et al., 2003; Aaltonen and Silow, 2008; Fu et al., 2009; MaciaszczykDziubinska et al., 2011; Villadangos et al., 2012), the last being the best studied microorganism where Acr3 acts as a metalloid/ $\mathrm{H}(+)$ antiporter for arsenite and antimonite. Poirel et al. suggest that $\operatorname{ars} B$ and $a c r 3$, arsenite transporter genes, are appropriate biomarkers of arsenic stress that may be suitable for further exploring the adaptive response of bacterial communities to arsenic in contaminated environments (Poirel et al., 2013).

The high-altitude Andean Lakes (HAAL) are ecosystems located in the South American Andes. The HAAL ecosystems are systems of shallow lakes formed during the Tertiary geological period (Seufferheld et al., 2008; Farias et al., 2011). These ecosystems are unique not only for their geographical characteristics and broad range of extreme environments but also for their abundant biodiversity (Fernandez Zenoff et al., 2006; Dib et al., 2008; Seufferheld et al., 2008; Flores et al., 2009; Ordoñez et al., 2009; Albarracín et al., 2011; Farias et al., 2013). In these environments high concentrations of arsenic were described in the water due to a natural geochemical phenomenon (Mantelli et al., 2003; Romero et al., 2003; Escudero et al., 2007; Dib et al., 2008, 2009; Escalante et al., 2009). The high concentration of arsenic present in HAAL is strongly limiting not only for human life but also for growth of many microorganisms (Valko et al., 2005) and selects development of arsenic tolerant bacteria (Dib et al., 2008; Ordoñez et al., 2009). Different concentrations of arsenic (maximum values) were reported in these environments, $2.3 \mathrm{mg}$ $\mathrm{L}^{-1}$ in Tebenquiche Lake (Farías et al., 2014), $9.1 \mathrm{mg} \mathrm{L}^{-1}$ in Salar de Llamara (Rasuk et al., 2014), $0.8-11.8 \mathrm{mg} \mathrm{L}^{-1}$ in Andean Lakes (Ordoñez et al., 2009), $0.9-28 \mathrm{mg} \mathrm{L}^{-1}$ in salt lakes (Lara et al., 2012). Recently, in other HAAL higher values were detected, namely arsenic values between 18.5 and $33.8 \mathrm{mg} \mathrm{L}^{-1}$ were observed in Laguna Socompa (Farias et al., 2011, 2013); these values are greater than the one reported for Mono Lake $\left(200 \mu \mathrm{M} \mathrm{HAsO}_{4}^{-2}\right.$, approximately $19.8 \mathrm{mg} \mathrm{L}^{-1}$ As) (Oremland et al., 2004). In this place, Farias and colleagues described stromatolites forming at an altitude of $3570 \mathrm{~m}$, developing in an alkaline, hypersaline environment, rich in inorganic nutrients and very rich in arsenic, and with mild temperatures $\left(20-24^{\circ} \mathrm{C}\right)$ due to a hydrothermal input (Farias et al., 2011, 2013).

The genus Exiguobacterium was one of the most widespread and representative genera on the HAAL, being detected by direct (pure culture isolation) and indirect (DGGE) techniques (Ordoñez et al., 2009). Exiguobacterium spp. have been isolated from, or molecularly detected in, a wide range of habitats including cold and hot environments with temperature ranging from -12 up to $55^{\circ} \mathrm{C}$ (Vishnivetskaya et al., 2006; Rodrigues and Tiedje, 2007). This fact confers substantial interest to the genus as a potential model system for the investigation of attributes that may correlate with adaptation and evolution of organisms to diverse thermal regimes (Vishnivetskaya et al., 2009). Several studies have shown that some strains of Exiguobacterium possess unique properties of interest for applications in biotechnology, bioremediation, industry and agriculture (Pattanapipitpaisal et al., 2002; Lopez et al., 2005; Okeke et al., 2007).

Recently, we presented the draft genome sequence of Exiguobacterium sp. S17, isolated from a stromatolite in L. Socompa (GenBank:ASXD00000000.1) and the draft genome sequence of Exiguobacterium sp. N139, a UV-B resistant bacterium isolated from L. Negra (GenBank:JMEH00000000). These strains represent an attractive model system for the study of environmental stress capable of growing readily in the laboratory. There is particular interest in the S17 strain given its arsenic-rich original niche. In a previous study, it was able to grow in high arsenic concentration, it tolerated arsenic concentration such as $10 \mathrm{mM}$ of As[III] and $150 \mathrm{mM}$ of As[V], but a proteomic approach did not detect unique nor arsenic specific proteins (Belfiore et al., 2013).

Based on these previous results, the aim of this study was to gain further insight into mechanisms of tolerance to high arsenic concentrations by analyzing the genome sequences of $\mathrm{S} 17$ and $\mathrm{N} 139$, recently isolated from HAAL extreme environments. We initially tested the arsenite and arsenate resistance of S17, N139 and model organisms. Interestingly, our experiments show that S17 has a greater resistance to arsenite than N139, but similar growth in arsenate. We then compared the genomes and identified that the only difference between both species regarding known arsenic resistant genes is the presence of an acr 3 gene in S17. To further understand the acr3 of S17 we analyzed 
the sequence and structural characteristics, which allowed us to identify the relevant residues.

\section{Materials and Methods}

\section{Strain Isolation and Culture Media}

The strain S17 was isolated in situ from L. Socompa stromatolite (Ordoñez et al., 2013) by plating samples on PY agar medium, containing per liter: $10 \mathrm{~g}$ peptone, $0.5 \mathrm{~g}$ yeast extract, $2 \mathrm{~mL}$ $\mathrm{MgCl}_{2} 1 \mathrm{M}, 2 \mathrm{~mL} \mathrm{CaCl} 21 \mathrm{M}, 2.4 \mathrm{~mL} \mathrm{FeSO}_{4} 0.5 \%$ and $1.5 \%$ $\mathrm{w} / \mathrm{v}$ agar, after incubation at room temperature, while the strain Exiguobacterium sp. N139 was isolated from water in L. Negra by plating in Lake medium (LM). The LM was used to maintain the same salinity as the isolation environment and was obtained by filtering lake water $(0.22 \mu \mathrm{m}$ Biopore filters $)$ and adding 2.5 $\mathrm{g}$ yeast extract and $12 \mathrm{~g}$ agar (Difco) per liter. Isolated N139 was then cultured in the same isolation medium at $20^{\circ} \mathrm{C}$ with shaking $(150 \mathrm{rpm})$. The strain Exiguobacterium aurantiacum DSM 6208, from the German Collection of Microorganisms and Cell Cultures (DSM) was included in the assays for comparison as external control.

To unify the tests, all cultures were routinely grown with shaking (150 rpm) in Luria-Bertani broth (LB) at $30^{\circ} \mathrm{C}$ overnight or in plates with LB medium supplemented with $1.5 \%$ agar (Britania). When indicated, LB was diluted to $50 \%$ final concentration $\left(\mathrm{LB}_{50}\right)$.

\section{Tolerance Toward Arsenic}

For qualitative assessment of arsenic tolerance in solid media, bacterial cultures collected at $\mathrm{OD}_{600 \mathrm{~nm}}$ of 0.4 were subjected to serial dilutions. $10 \mu \mathrm{l}$ aliquots were plated onto $\mathrm{LB}_{50}$ agar plates, supplemented with different concentrations of sodium arsenate $(\mathrm{As}[\mathrm{V}])$ and sodium arsenite (As[III]) as indicated in Figure 2.

To quantify the resistance toward arsenic of the studied strains, cultures were grown at different concentrations of this agent. Overnight cultures were diluted to an initial $\mathrm{OD}_{600 \mathrm{~nm}}$ between 0.05 and 0.09 into fresh $\mathrm{LB}_{50}$ medium supplemented with different concentrations of arsenic: $2.5 \mathrm{mM}, 5 \mathrm{mM}$ and $10 \mathrm{mM}$ of sodium arsenite (As [III]); 50, 100, and $150 \mathrm{mM}$ of sodium arsenate (As [V]). A non-supplemented sample was used as positive control. The cultures were incubated at $30^{\circ} \mathrm{C}$ with shaking for $24 \mathrm{~h}$, and $\mathrm{OD}_{600 \mathrm{~nm}}$ was measured with a spectrophotometer Ultrospec 10 cell density meter (Amersham Biosciences).

\section{Phylogenetic Analyses of Sequenced Exiguobacterium spp.: 16S rRNA, Multilocus Sequence Analysis (MLSA), Acr3 and ArsB Proteins}

We used 7 genomes of Exiguobacterium in these phylogenetic analyses (Table 1). MLSA was based on the concatenated sequences of house-keeping genes (Brown et al., 2001; Thompson et al., 2009). The 16S rRNA gene sequences, the gene sequences used for MLSA (i.e., fts $Z, g y r B, m r e B, p y r H, r e c A, r p o A$, and topA) and protein sequences of the ArsB and Acr3 families were obtained from the National Center for Biotechnology Information (NCBI). RAST server (Aziz et al., 2008) was used to annotate the draft genomes.

Sequences were aligned using CLUSTAL X 2.0.9, a Windows interface for the multiple alignment program ClustalW (Larkin et al., 2007). Phylogenetic analyses were carried out with the program MEGA 5 (Tamura et al., 2011), using the neighborJoining method (Saitou and Nei, 1987). All positions containing gaps in the datasets were removed, and the confidence intervals obtained by this method were positioned using the bootstrap procedure, performing 1000 replicates (Saitou and Nei, 1987).

\section{RNA Extraction and RT-PCR}

Exiguobacterium sp. S17 was grown overnight in $50 \mathrm{ml}$ of $\mathrm{LB}_{50}$ and $\mathrm{LB}_{50}$ with $7.5 \mathrm{mM}$ of As [III] or $100 \mathrm{mM}$ of $\mathrm{As}[\mathrm{V}]$. Twenty-five milliliters of each culture were used for RNA extraction. Cells were harvested by centrifugation (9200 g at $4^{\circ} \mathrm{C}$ during $5 \mathrm{~min}$ ) and pellets were suspended in $1 \mathrm{ml}$ of Quick-zol, total RNA was extracted following the protocol proposed by the supplier (Quick-Zol- Kalium Technologies). Acr3 differential expression was assessed by RT-PCR using the specific primers designed from the genome of S17 strain (ACR3F1: 5'-CTTGGCTTCGCGATTGGACTGAG3' ACR3R1: 5'-GACACGGCGGCTTATGGCAAAAT3') and 16S primer (357F: 5'-TACTGATAGAA.

TGTGGAGC-3' -518R: 5'-CGT ATT ACC GCG GCT GCT GG-3') was used as housekeeping gene. The reverse transcription was performed with ImProm-II TM Reverse Transcriptase (Promega), following the protocol recommended by the supplier.

TABLE 1 | Genomic features and number of arsenic resistance genes observed in Exiguobacterium genomes.

\begin{tabular}{|c|c|c|c|c|c|c|c|c|c|c|c|}
\hline Organism & Accession number & $\begin{array}{l}\text { Genome } \\
\text { size }(\mathrm{mb})\end{array}$ & $\begin{array}{c}\mathrm{G}+\mathrm{C} \\
(\mathrm{mol} \%)\end{array}$ & $\begin{array}{r}\text { Number } \\
\text { of CDS }\end{array}$ & $\begin{array}{l}\text { Number } \\
\text { of contigs }\end{array}$ & Acr3 & ArsB & ArsA & ArsR & ArsD & ArsC \\
\hline Exiguobacterium sp. S17 & ASXD00000000.1 & 3.13 & 53.1 & 3218 & 163 & 1 & 1 & 1 & 1 & 1 & 2 \\
\hline Exiguobacterium sp. N139 & JMEH00000000 & 2.95 & 52 & 3007 & 45 & 0 & 1 & 1 & 1 & 1 & 2 \\
\hline Exiguobacterium sibiricum 255-15 & CP001022.1 & 3.04 & 47.7 & 3015 & 1 & 0 & 1 & 0 & 1 & 0 & 1 \\
\hline Exiguobacterium antarcticum B7 & СР003063.1 & 2.82 & 47.5 & 2772 & 1 & 0 & 1 & 0 & 1 & 0 & 1 \\
\hline Exiguobacterium sp. AT $1 \mathrm{~b}$ & СР001615.1 & 3.00 & 48.5 & 3020 & 1 & 0 & 1 & 1 & 1 & 1 & 1 \\
\hline
\end{tabular}




\section{Orthologous Analysis Using Bidirectional Best Hits}

An analysis of orthologous was done comparing coding sequences present in S17 and N139 contigs, in order to explain the resistance to arsenic in both organisms. Bidirectional Best Hits (BBHs) relation was applied as described in Overbeek et al. (Overbeek et al., 1999). E-value cutoff of 1E-05 was used in Blast search and a $90 \%$ coverage cutoff was added to the criteria in order to obtain more trusted relationships. Numbers of genes belonging to $\mathrm{BBH}$ relation in both organisms are shown in Table S1 (see Supplementary Materials).

\section{Transmebrane Segment Prediction}

In this work we use four predictors of transmembrane segments: TMHMM (Krogh et al., 2001), DAS (Cserzö et al., 1997), HMMTOP (Tusnády and Simon, 2001), TOPCONS (Bernsel et al., 2009), plus two other general secondary structure predictors: PSIPRED (Jones, 1999), PORTER (Pollastri and McLysaght, 2005). A majority voting consensus was calculated, assigning transmembrane segment structure if 4 or more predictors agree.

\section{Template Alignment and Model Building for S17 Acr3}

To find a suitable template for model construction, 5 iterations of PSI-Blast (Altschul et al., 1997) were performed to build a profile for the Exiguobacterium S17 Acr3 protein using UniRef90 (Suzek et al., 2007) and 1E-05 as gathering threshold. Using this profile, another PSI-Blast iteration was computed against a library of templates. This library was constructed using each amino acid sequence underlying the PDB structures and clustering over their sequences was done using CD-HIT (Li et al., 2001) to admit at least 95\% sequence identity between them. MODELLER (Sali and Blundell, 1993) was used to produce several models based on this alignment and the best model was chosen using ProQM Server (Ray et al., 2010) for model quality assessment.

\section{Results}

\section{Phylogenetic Reconstructions by 16S rRNA and MLSA}

The study of HAAL allowed isolation of bacteria resistant to UVR, antibiotic, arsenic and other extreme factors (Fernandez Zenoff et al., 2006; Dib et al., 2008; Flores et al., 2009; Ordoñez et al., 2009). In this place a predominance of Exiguobacterium spp. was observed (Ordoñez et al., 2009) and the strains N139 and S17 were assigned to this genus by 16 S rRNA sequence analysis.

In this work were selected both conserved and variable single copy genes from the Exiguobacterium genomes, belonging to different functional groups used in several taxonomic studies (Brown et al., 2001; Thompson et al., 2009). Neighbor-Joining and maximum likelihood trees based on 16S rRNA gene sequences (Figure 1A) and MLSA (Figure 1B) showed similar topology using both markers. Bootstrap analysis indicated that most branches were highly significant. The phylogenetic reconstruction indicated a clear separation of groups of temperate (i.e., S17, N139, RW-2, 8-11-1, and AT1b) and cold (i.e., 255-15 and B7) origin. S17 was closely related to 8-11-1 and N139 to RW-2, all forming a single clade, while the strain Exiguobacterium sp. AT1b was located distant from these. On

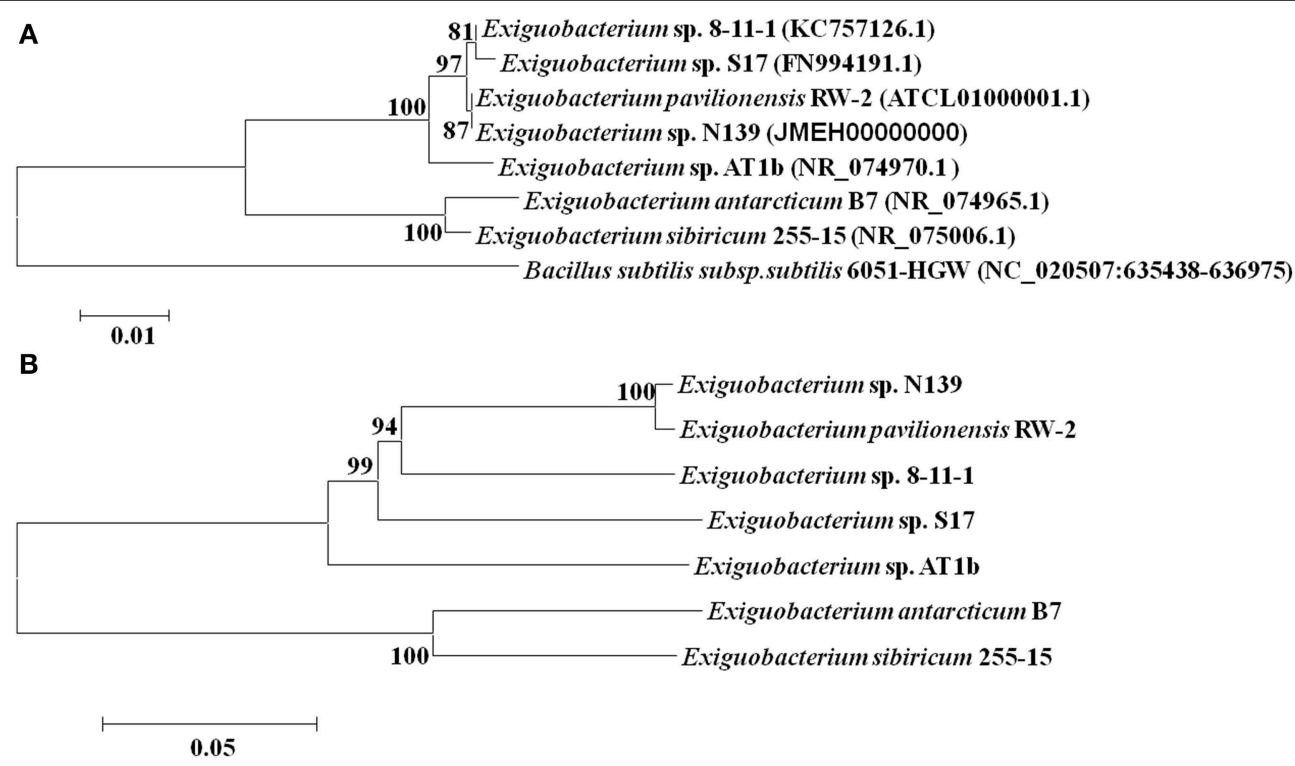

FIGURE 1 | Phylogenetic analyses of sequenced Exiguobacterium spp. Phylogenetic tree based on 16S rRNA gene sequences (A) and based on MLSA of eight housekeeping genes (ie. ftsZ, rpoA, recA, topA, gapA, $m r e B$, gyr $B$, and $p y r H)(\mathbf{B})$. The sequences included in the analysis were obtained from the National Center for Biotechnology Information (NCBI). The evolutionary history of Exiguobacterium strains was inferred using the Neighbor-Joining method (Saitou and Nei, 1987) with 1000 repetitions. Robustness of the major branch points is indicated by bootstrap values. Phylogenetic analyses were performed with the program MEGA 5.05 (Tamura et al., 2011). 
the other hand, Exiguobacterium sp. B7 and 255-15 formed a different clade with high similarity between them.

\section{Tolerance to Arsenic}

Soluble arsenic is present in nature as arsenate $(\mathrm{As}[\mathrm{V}])$ and arsenite (As[III]), the latter being more toxic. Tolerance against arsenic was firstly evaluated by placing drops of serially diluted culture of the studied strains on $\mathrm{LB}_{50}$-agar plates, supplemented with different concentrations of arsenate or arsenite as sodium salt (see Materials and Methods). Exiguobacterium sp. S17 and N139 were compared, since both were isolated from a HAAL, whereas DSM 6208 was used as external control in all assays.

Exiguobacterium sp. S17, N139 and control strain DSM 6208 showed tolerance to As[V], being able to grow at concentrations up to $100 \mathrm{mM}$ (Figure 2A). Interestingly, only the S17 strain was able to tolerate and grow at concentrations above $5 \mathrm{mM}$ arsenite As[III] in culture media, while strains N139 and DSM 6208 did not grow at concentrations higher than $2.5 \mathrm{mM}$ arsenite (Figure 2B). To quantify the inhibition due to arsenic in the culture medium, assays at different concentrations were performed in liquid media and final $\mathrm{OD}_{600 \mathrm{~nm}}$ after $12 \mathrm{~h}$ of growth was determined. As shown in Figure 2C, growth of the HAALs isolates (S17 and N139) was similar to that of the control strain at all tested As[V] concentrations up to $150 \mathrm{mM}$. In contrast, at $10 \mathrm{mM}$ As[III], Exiguobacterium N139 and DSM 6208 showed a $90 \%$ decline in growth, reaching $\mathrm{OD}_{600 \mathrm{~nm}}$ values of $5-10 \%$ of the corresponding control without arsenic (Figure 2D). The S17 strain tolerated all tested concentrations of the metalloid, showing only a minor impairment in growth at $10 \mathrm{mM}$ of $\mathrm{As}(\mathrm{III})$ (Figure 2D).

\section{Comparative Analysis of Arsenic Detoxification Genes from Exiguobacterium Genomes}

In this work we used the sequence data of genes related to arsenic resistance from five sequenced Exiguobacterium genomes obtained from the NCBI. The characteristics, the source and the accession number of these strains are shown in Table 1. These data were utilized for comparison with the genome of Exiguobacterium sp. S17 and N139.

Analysis of orthologous genes shows a similar relationship between the genomes to that inferred using 16S rRNA and MLSA (see Table S1 in Supplementary Materials). As pictured in Figure 3, S17 and N139 genomes share 2221 ORFs which corresponds to $68.9 \%$ of total ORFs for S17 and 73.6\% for N139. Differences between S17 and N139 biological subsystems were studied using RAST annotations assigned to non-orthologous genes (Table S2, see Supplementary Materials). Most of them were not assigned by RAST as to be in a particular subcategory: 595 and 581 for N139 and S17, respectively. In the "Virulence, Disease and Defense" category some differences were found. N139 possessed several subsystems apparently absent from S17, including genes related to tolerance of Mercury (3 ORFs), Copper (4 ORFs) and Cadmium (6 ORFs). Interestingly, S17 compared to $\mathrm{N} 139$, in addition to some antibiotic resistance features (3 ORFs), contains an arsenical resistance efflux pump Acr3. This seems to

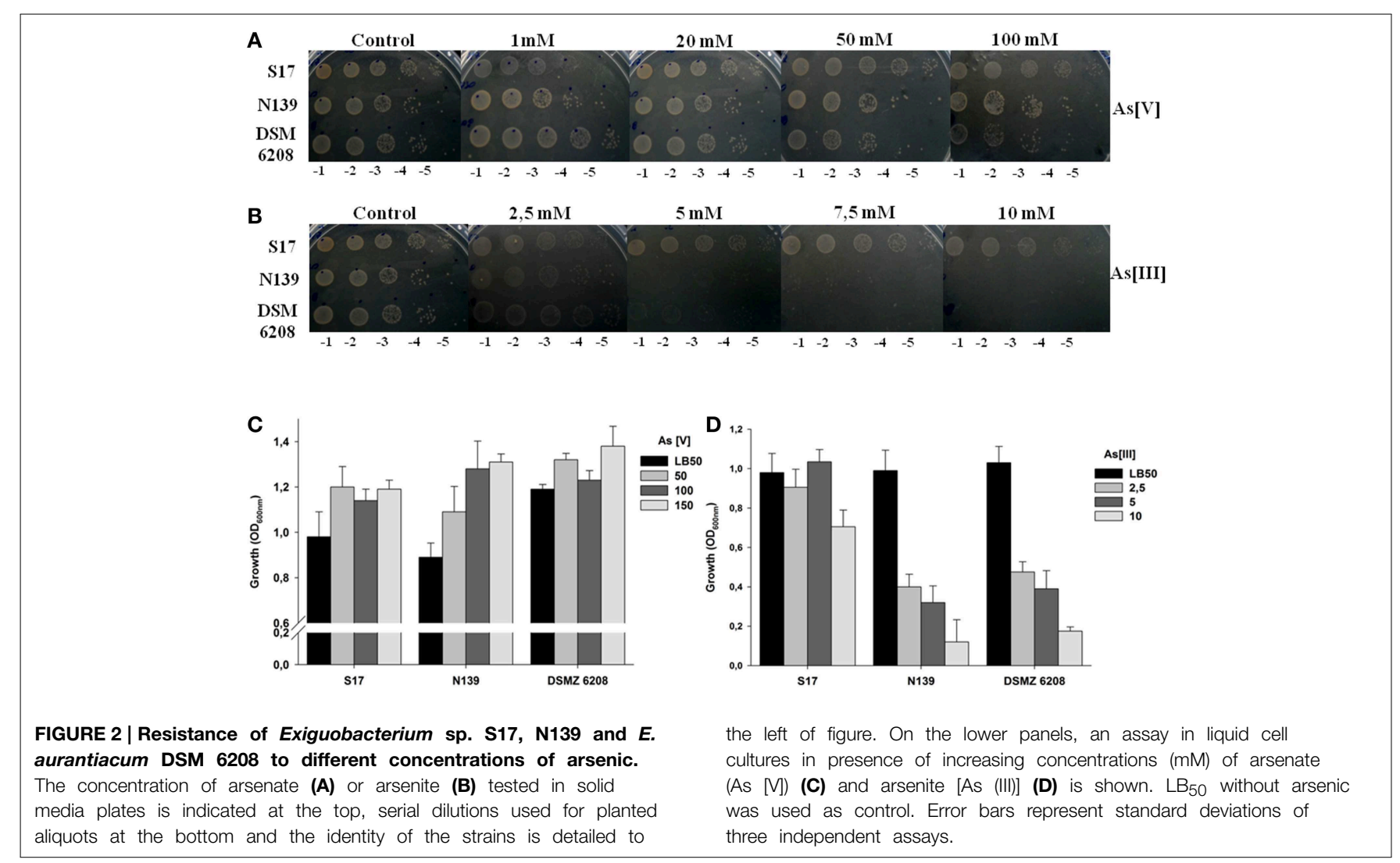




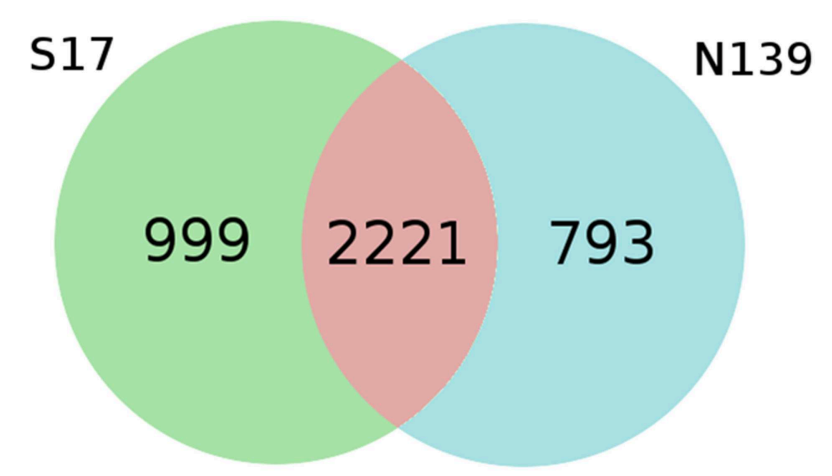

FIGURE 3 | Venn diagram deduced from bidirectional best hits between $\mathbf{S 1 7}$ and N139. Both organisms share $68.9 \%$ and $73.6 \%$ over total ORF count for S17 and N139, respectively. Evalue cutoff of 0.00001 and a coverage cutoff of $90 \%$ were used in bidirectional blastp searches.

be the main difference between N139 and S17 in terms of arsenic tolerance as defined by RAST.

Genetic organization of the arsenic resistance genes from the different strains is shown in Figure 4. Most of these genes are organized in two versions of the ars operon, arsRBC being the simplest configuration. The other configuration includes the genes $\operatorname{arsRDAXB}$ ( $\mathrm{X}$ is annotated as a hypothetical protein). As shown in Figure 4, strains B7 and 255-15 have the smaller number of arsenic resistant genes, comprising the arsRBC basic detoxification system. S17, N139, AT1b, 8-11-1, and RW2 have the additional ars $D$ and ars $A$ genes, which would provide a more effective detoxification. In turn, S17 has a second unique cytoplasmic arsenite extrusion pump, the acr3 gene, being the first time this gene is reported in the genus Exiguobacterium. In all cases $\operatorname{ars} C$ is not included in the operon, and in a few cases two ars $C$ copies are found in the genomes (i.e., S17, N139 and 8-111). The acr3 gene from S17 is not located in the operon with the other arsenic resistance genes. The genetic organization matches the 16S rRNA and MLSA distribution, thus B7 and 255-15, which group together in those trees (Figures 1A,B), have a short version of the operon, while the strains S17, N139, AT1b, 8-11-1, and RW2, which form another clade in the tree, show an extended operon.

\section{Expression of acr3 in $\mathbf{S 1 7}$ Strain}

To assess the presence of the acr3 transcript gen in S17, this strain was grown in presence and absence of arsenic in three different conditions: As[III] $7.5 \mathrm{mM}$, As[V] $100 \mathrm{mM}$, and control without As. RT-PCR was performed and the obtained cDNA was used to amplify the acr3 gen with specific primers (ACR3F1-ACR3R1). The obtained results indicate that the acr 3 gene is expressed and its expression is constitutive (Figure S7).

\section{Phylogenetic Tree of ArsB and Acr3}

Resistance toward As[III] has been shown to be related to the presence of membrane efflux proteins which extrude this toxic species (Paez-Espino et al., 2009), that are included in the ArsB or in the Acr3 families. We performed a phylogenetic analysis of the proteins from Exiguobacterium, comparing them with other known protein sequences obtained from NCBI.

For the ArsB proteins, the resulting phylogenetic tree showed a distribution based on their affiliation, displaying two groups consisting of Gram negative and Gram positive members (Figure 5A). The sequences of the Exiguobacterium genus grouped with the latter. The topology of this subtree was identical to the topology observed in the 16S rRNA tree (Figure 1A).

On the other hand, the Acr3-like proteins have been classified into three subgroups, which are independent of the taxonomic affiliation (Figure 5B). The only known sequence from the Exiguobacterium genus, the protein Acr3 from Exiguobacterium sp. S17, grouped in the third less characterized cluster, together with other proteins from Gram positive bacteria (Firmicutes and Actinobacteria).

\section{Structural Analysis of Acr3 and ArsB Efflux Pumps}

To characterize the newly identified acr3 gene in the Exiguobacterium genus we performed an structural bioinformatic approach to predict its structure and identify key residues. Initially four transmembrane segment predictors (TMHMM, DAS, HMMTOP, TOPCONS) and two general secondary structure predictors (PSIPRED, PORTER) were used in order to predict BsAcr3 topology (Figure S2, Supplementary Materials). We identified 10 transmembrane helices and the residues located in the cytoplasm and in the extracellular part. We selected the structure 3zuxA (Sodium Bile symporter) which has a $16 \%$ identity and $93 \%$ coverage (see Figure S1 in Supplementary Materials) to perform the modeling as described in the Materials and Methods Section. ProQM analysis of the model results in a quality score of 0.714 (0-low, 1-high), which represents a good model despite the low identity.

Moreover, for model validation, an alignment was computed with other two Acr3 sequences: Bacillus subtilis Acr3 (BsAcr3) (Aaltonen and Silow, 2008) and Alkaliphilus metalliredigens Acr3 (AmAcr3) (Fu et al., 2009). BsAcr3 and AmAcr3 were chosen because the accessibility of certain residues for their localization in intracellular and extracellular loops has been studied. In the case of BsAcr3, accessibility was analyzed with PhoA and GFP. For AmAcr3 a scanning cysteine accessibility method (SCAM) (Bogdanov et al., 2005) was used to determine the transmembrane topology. The alignment between these three protein sequences was computed using HMMER3 (Finn et al., 2011) with the Acr3 family HMM (TIGR00832-acr3: arsenical-resistance protein) from the TIGRFAM database (Haft et al., 2001). Using this information the residues that belong to intracellular and extracellular sides were mapped in the structure (Figure 6) and in the alignment (Figure S3 in Supplementary Materials).

As can be seen in Figure 6A, residues from S17 Acr3 that aligned to residues previously determined to be outside by SCAM fall in loops outside the transmembrane regions. There is an exception for the leucine at position 137, but, as Aaltonen et al. pointed out -referring to a corresponding methionine in that position-, although that seems to contradict the transmembrane predictors due to its position in the middle of a transmembrane 


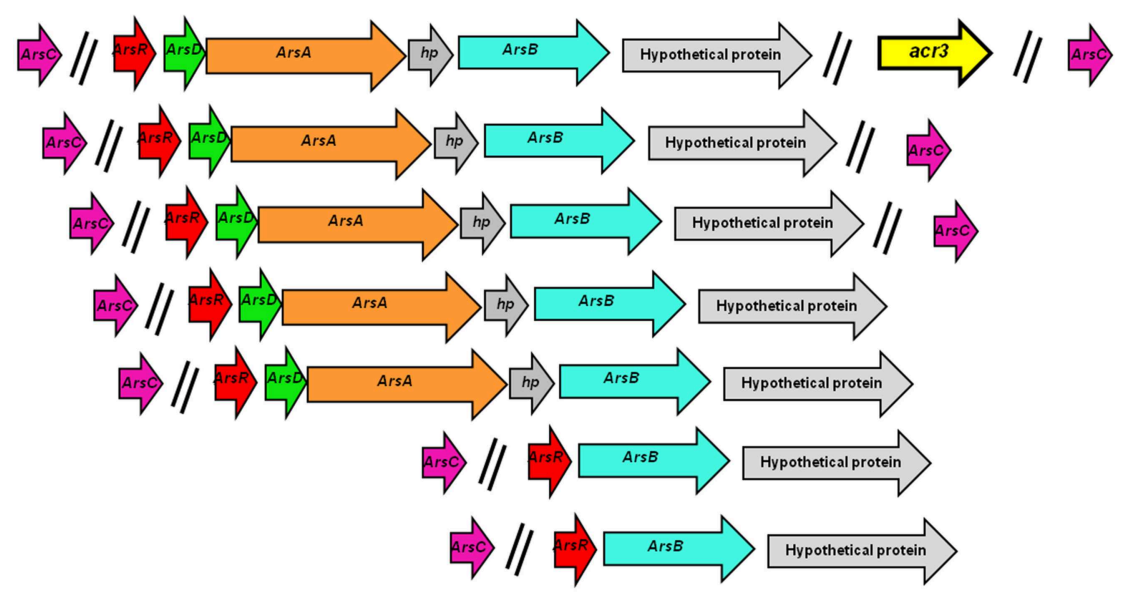

S17

N139

8-11-1

AT1b

RW-2

255-15

B7

FIGURE 4 | Arsenic resistance genes in sequenced

Exiguobacterium spp. Genetic organization of the genes colored by function. Extrusion pumps ars $B$ is shown in blue and acr3 in yellow;
arsA (ATPase) genes in orange; arsC (arsenate reductase) in violet, regulatory genes (ars $R$ and $a r s D$ ) in red and green, and hypothethical proteins in gray. helix (Aaltonen and Silow, 2008), there is a region that opens and close to transport the ligands across the membrane that could explain its solvent accesibility. Also, there are regions where a transmembrane segment presents a breakdown of alpha helix forming small helical hairpins reported to be a common motif in ion transporters (Screpanti and Hunte, 2007). These helical hairpins are between positions residue 106-109 and residue 263266, and seem to be important for Acr3 function because, as can be seen in Figure 6B, a conserved cysteine which is essential for the protein function is at position 107 which is in the core region of the protein placed in one of these hairpins.

Based on the analysis by $\mathrm{Hu}$ et al. on the Sodium/Bile Acid symporter that we have used as template structure ( $\mathrm{Hu}$ et al., 2011), Acr3 seems to present two domains, a panel domain and a core domain, depicted in green and gray in Figure 6B. We also highlighted positively and negatively charged residues. As can be seen, the intracellular region is extremely populated with positive residues (Arg3, Arg57, Arg63, Arg177, Arg191, Arg241, Arg242, Arg249, Lys6, Lys119, Lys182, Lys245, Lys246) compared with the negative residues (Asp121, Asp251, Glu5, Glu190). Meanwhile, in the extracellular side, there are more negative residues (Asp33, Asp91, Glu26, Glu217, Glu250, Glu280) than positive ones (Arg29, Arg30, Arg213). The arsenite $\mathrm{pKa}$ is 9.2 and the Exiguobacterium genus is known to be alkaliphile so a few percent of arsenite would be ionized in the cytosolic side of the membrane involving positively charged residues in electrostatic interactions with arsenite due to its negative charge.

Interestingly, there are three charged residues (Arg264, Asp109, Glu294) in the core of transmembrane segments but particularly near to Cys107 and the four of them are placed right in the interface between the core domain and the panel domain. These residues could be involved in the arsenite binding together with the Cys residue. Finally, a protein cavity entrance can be appreciated in Figure 6C, which can be contrasted with Figure 6B to see how this entrance is between the two panels, it is clear that previously mentioned leucine (Leu147 in S17 Acr3), as mentioned above, presents cytoplasmic accesibility evidence due to its position in the protein.

Transmembrane topology prediction was done for S17 arsB gene using sequence based predictors and results can be seen in Figure S4 and S5 (see Supplementary Materials). The arsB gene encodes a membrane protein of 428 amino acids in S17 and N139, showing an amino acid sequence homology of $93.5 \%$ identity between them. The amino acid sequence identity of ArsB from S17 with the protein from E. sibiricum 255-15 was 82.6\%; E. antarcticum B7 83.3\%; E. pavilionensis RW-2 93.8\%; Exiguobacterium sp. AT1b $91.7 \%$ and Exiguobacterium sp. 8-11-1 $93.8 \%$, while N139-ArsB showed an identity of $83.3 \%$ with $255-$ $15 ; 84.4 \%$ with B7, $98.9 \%$ with RW-2, 93.5\% with AT1b and $96.4 \%$ with 8-11-1. It was observed that ArsB contains 11 probable transmembrane helices predicted by TMHMM2.0 in S17 and N139 (Figure S6, Supplementary Materials). Analysis of several published genome sequences of Exiguobacterium strains showed that the $a r s B$ gene is conserved in this genus and a similar activity is expected.

\section{Discussion}

In this work, three topics were specially emphasized. First, arsenic tolerance of Exiguobacterium sp. S17 and N139, isolated from extreme environments with different natural concentrations of arsenic, were compared. Second, the genomes of S17 and N139 were searched for arsenic resistance genes that were compared between strains. Finally, in-silico modeling was performed with the extrusion pumps ArsB and Acr3, and the first 3D model for the Acr3 protein was obtained to characterize this relevant gene.

With respect to the first topic, the tolerance to arsenic was also studied in the two mentioned strains plus a third strain as a control (DSM 6208). S17 was in fact the only strain able to tolerate and grow at concentrations above $5 \mathrm{mM}$ arsenite (As[III]) (Figures 2B,D). In turn, all strains grew well 


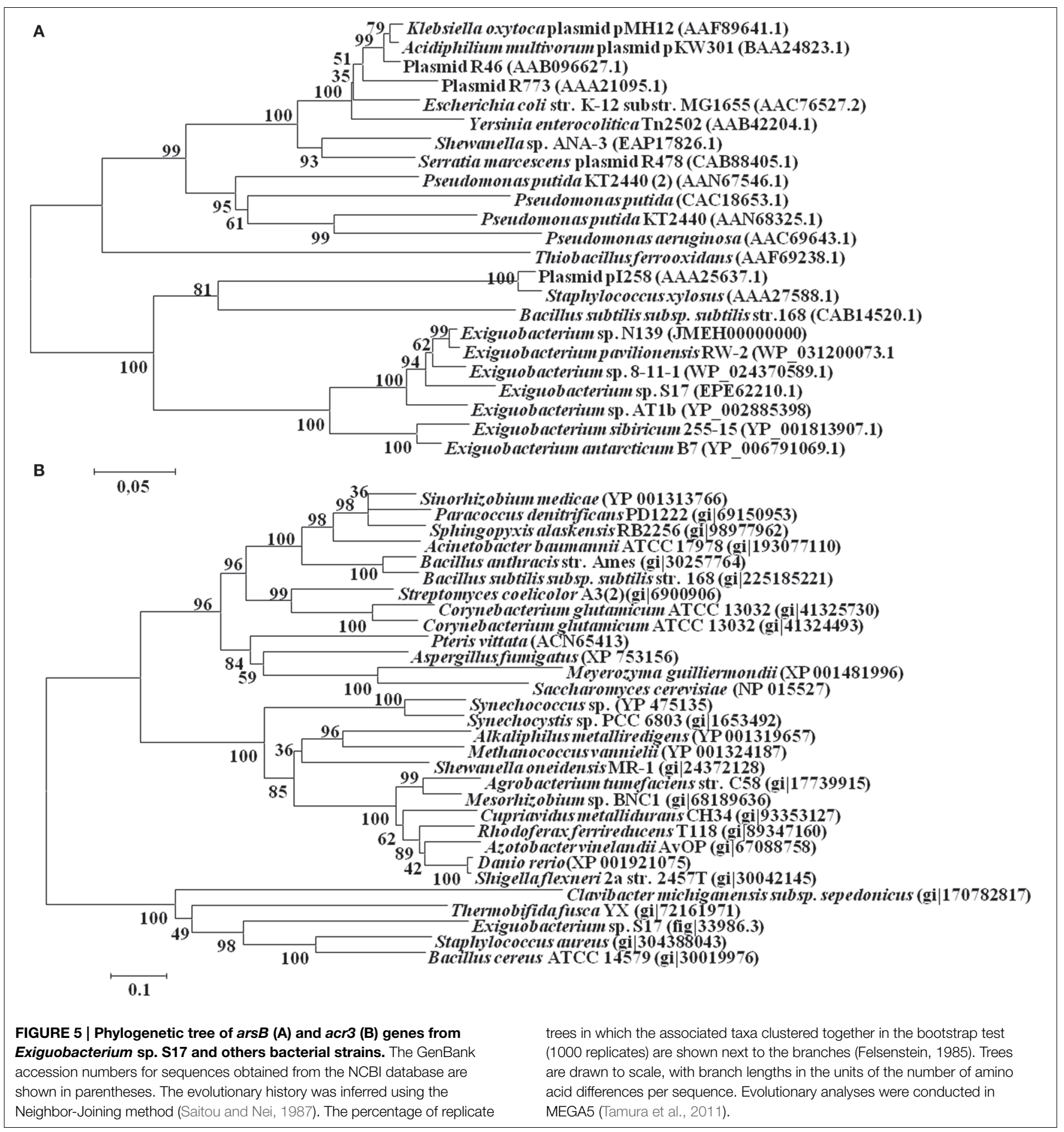

at increasing concentrations of arsenate (As[V]) (Figures 2A,C). Interestingly, growth was better with $\mathrm{As}[\mathrm{V}]$ than for the nonsupplemented cultures, implying that it somehow enhances growth. Belfiore et al. showed that glycolysis proteins seem to be more abundant in the S17 strain grown in presence of $\mathrm{As}[\mathrm{V}]$, suggesting a more active metabolism which would explain the increased growth in a set timeframe (Belfiore et al., 2013).
While known arsenic resistance systems are the main factors responsibles for the arsenic tolerance, additional mechanisms might also influence the extreme resistance of the S17 strain. A possible resistance mechanism could be the presence of methylases, as described for Rhodopseudomonas palustris (Qin et al., 2006) and cyanobacteria (Yin et al., 2011), although conserved arsenic-methylase genes were not detected neither 

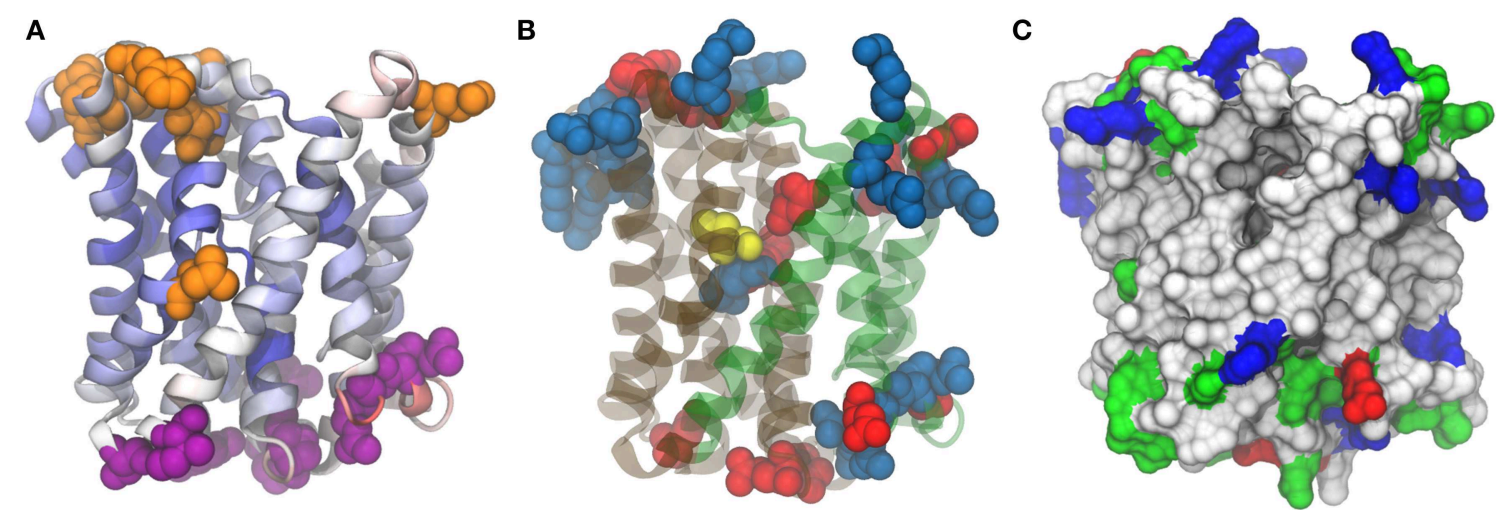

FIGURE 6 | Model structure for Acr3 efflux pump. 3zuxA (Sodium-bile acid symporter) was used as template and the alignment presents $16 \%$ identities and 95\% coverage on Acr3 sequence. (A) Quality assessment. Position color means quality assesment per residue acording to ProQM estimation, blue-good and red-worse. Orange residues correspond to those that present experimental evidence as exposed to cytosol and violet residues correspond to those exposed to periplasm. (B) Conserved cysteine (yellow), negatively charged residues (red) and positively charged residues (blue). (C) Surface visualization with hydrophobic residues (white), polar residues (green), negative charged residues (red) and positive charged residues (blue). on the S17 genome (Ordoñez et al., 2013) nor proteome (Belfiore et al., 2013). Tolerance might also be enhanced by indirect mechanisms coping with other stresses generated by arsenic, such as oxidative stress. The proteomic study did detect overexpression of superoxide dismutase (SOD) and universal stress proteins, both in presence of As[III] and As[V] (Belfiore et al., 2013). These results are consistent with previous findings reported by Sacheti et al. (2014) and Ciprandi et al. (2012).

Regarding the second topic, whole genome sequencing and comparative genome analysis by BBHs of S17 and N139 allows us to determine that the genomes of both organisms share 2515 genes considered orthologous (Figure 3). Those genes correspond to 78.1 and $83.6 \%$ of the genes predicted in S17 and $\mathrm{N} 139$, respectively. $\mathrm{BBH}$ analysis indicates that S17 and N139 share all arsenic resistance genes, except for the presence of the Acr3 efflux pump in S17. Although we cannot be completely sure whether other detoxification systems exist in the genome and other genes could may not have been identified (Bakke et al., 2009; Poptsova and Gogarten, 2010; Richardson and Watson, 2013), the whole set of arsenic resistance genes was clearly identified and manual annotation was performed.

Comparative analysis of arsenic detoxification genes from sequenced Exiguobacterium genomes showed that most of the genes are organized in two versions of the ars operon, arsRBC being the simplest configuration (i.e., strains B7 and 255-15) and the other configuration includes the genes arsRDAXB (S17, N139, AT1b, 8-11-1, and RW2). Surprisingly, the S17 strain displayed also an uncommon version of a pump that expels cytoplasmic arsenite, the acr3 gene (Figure 4). As was mentioned before, there are two efflux pumps, ArsB and Acr3, in this group of bacteria. While ArsB pump was found in all sequenced Exiguobacterium genomes, Acr3 was only found in the S17 strain. Moreover, in this work we demonstrated that the acr3 gene in S17 is constitutively expressed as is observed in all conditions tested (Figure S7).

With respect to the third topic, the Acr3 efflux pump, we modeled the structure and showed that our structure is in agreement with previous experiments that identified non-membrane residues. As mentioned before, a Cys residue conserved in all members of Acr3 family has been previously reported as the only cysteine required to achieve As(III) detoxification (Fu et al., 2009). In the case of this protein, Cys107 is the only cysteine in the protein, located right in the middle of a clear channel in our structure, that we now propose as the catalytic residue that binds arsenite.

Predicted topology is consistent with previous proposals for Bacillus subtilis and Alkaliphilus metalliredigens by Aaltonen et al. and Fu et al., respectively (Aaltonen and Silow, 2008; Fu et al., 2009). Ten transmembrane segments were predicted by transmembrane predictors and by homology modeling for Acr3 (Figure 6). Also, general purpose predictors are able to capture interesting secondary structure elements such as helical hairpins breaking two alpha helices in the same place as the conserved cysteine (Cys107) as mentioned in results section. This prediction agrees with the model based on a Sodium/Bile Acid symporter where there are two loops in the same region.

Based on the results presented here and previous works mentioned before, we propose that the main resistance mechanism of Exiguobacterium sp. S17 to arsenic would be the reduction of arsenate to arsenite and subsequent extrusion through membrane pumps as ArsB and Acr3 (Figure 7). Acr3 presents the conserved residues required for functionality as observed by Aaltonen and Silow (2008), Fu et al. (2009), and Maciaszczyk-Dziubinska et al. (2014) and would confer high resistance to arsenite (As[III]). Also, other mechanisms that overcome oxidative stress caused by arsenic would also help in the resistance to the metalloid.

The increased abundance of acr3 gene in environments with high arsenic concentration has been reported in the literature (Achour et al., 2007; Cai et al., 2009), and this seems also the case for Socompa, where a variety of microorganisms isolated from this site bear a copy of the gene, as can be seen in the genomes of Sphingomonas sp. S17 (AFGG01), Salinivibrio sp. strains S10B, S34, and S35 (AQOE01, APMS01, AQOD01). The gene is also present in other isolates of similar locations from 


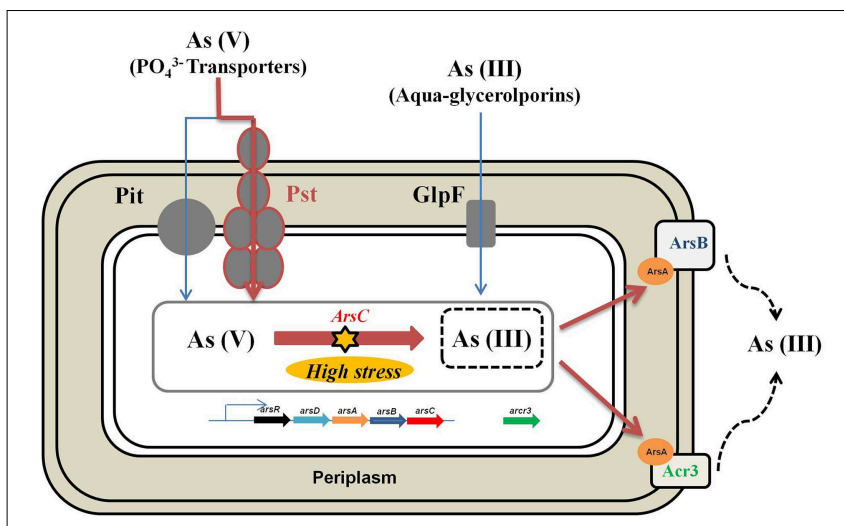

FIGURE 7 | Schematic representation of genes and proteins involved in the arsenic resistance in Exguobacterium sp. S17. The main arsenic resistance mechanism would be the reduction of arsenate to arsenite and subsequent extrusion through membrane pumps such as ArsB and Acr3.

the Argentinean Puna, namely Halorubrum sp. Strain AJ67 (CBVY01) and Acinetobacter sp. Ver3 (JFYL01). These data highlights the importance of acr3 in the environment, and is also supported by the absence of acr3 in the known Exiguobacterium strains isolated from non-contaminated locations. Finally, while the HAAL strains presented higher resistance to arsenic than the control strain DSM 6208, the structural analysis of Acr3 and ArsB efflux pumps showed that the arsB gene is conserved in this genus, so enhanced resistance to arsenite (As[III]) in S17 may be explained by the combined work of the two membrane proteins ArsB and Acr3. Therefore, according to these

\section{References}

Aaltonen, E. K., and Silow, M. (2008). Transmembrane topology of the Acr3 family arsenite transporter from Bacillus subtilis. Biochim. Biophys. Acta 1778, 963-973. doi: 10.1016/j.bbamem.2007.11.011

Achour, A. R., Bauda, P., and Billard, P. (2007). Diversity of arsenite transporter genes from arsenic-resistant soil bacteria. Res. Microbiol. 158, 128-137. doi: 10.1016/j.resmic.2006.11.006

Albarracín, V. H., Dib, J. R., Ordoñez, O. F., and Farias, M. E. (2011). “A harsh life of indigenous proteobacteria at the andean mountains: microbial diversity and resistance mechanisms towards extreme conditions," Book Series: Microbiology Research Advances, ed M. L. Sezenna (Hauppauge, NY: Nova Publishers), 91-131.

Altschul, S. F., Madden, T. L., Schaffer, A. A., Zhang, J., Zhang, Z., Miller, W., et al. (1997). Gapped blast and psi-blast: a new generation of protein database search programs. Nucleic Acids Res. 25, 3389-3402. doi: 10.1093/nar/25.17.3389

Aziz, R. K., Bartels, D., Best, A. A., DeJongh, M., Disz, T., Edwards, R. A., et al. (2008). The RAST server: rapid annotations using subsystems technology. BMC Genomics 9:75. doi: 10.1186/1471-2164-9-75

Bakke, P., Carney, N., Deloache, W., Gearing, M., Ingvorsen, K., Lotz, M., et al. (2009). Evaluation of three automated genome annotations for Halorhabdus utahensis. PLoS ONE 4:e6291. doi: 10.1371/journal.pone.0006291

Belfiore, C., Ordoñez, O. F., and Farias, M. E. (2013). Proteomic approach of adaptive response to arsenic stress in Exiguobacterium sp. S17, an extremophile strain isolated from a high-altitude Andean Lake stromatolite. Extremophiles 17, 421-431. doi: 10.1007/s00792-013-0523-y

Bernsel, A., Viklund, H., Hennerdal, A., and Elofsson, A. (2009). TOPCONS: consensus prediction of membrane protein topology. Nucleic Acids Res. 37, W465-W468. doi: 10.1093/nar/gkp363 results, the appearance of Acr3 may explain the improvement in arsenic tolerance in environments with high arsenic content.

\section{Author Contributions}

$\mathrm{OO}$ and EL performed the research and wrote the paper. OO performed physiological experiments and data analysis, EL performed annotation, comparative genome analysis and structural modeling. DK carried out phylogenetic analysis and helped to modify the manuscript; MF, NC, and AT obtained funding for the original project idea. All authors read and approved this manuscript.

\section{Acknowledgments}

This work was supported by the Argentinean National Council for Science and Technology (CONICET; PIP 0365/12), the Argentinean National Fund for Science and Technology (FONCyT; project PICT numbers 1788 and 2805). We also want to thank Secretaria de medio ambiente de la provincia de Salta for his assistance in field trip. $\mathrm{OO}$ is a recipient of a posdoctoral fellowship from Bunge and Born Foundation and EL is a recipient of a doctoral fellowship from CONICET Argentina.

\section{Supplementary Material}

The Supplementary Material for this article can be found online at: http://journal.frontiersin.org/article/10.3389/fenvs. 2015.00050

Bogdanov, M., Zhang, W., Xie, J., and Dowhan, W. (2005). Transmembrane protein topology mapping by the substituted cysteine accessibility method (SCAM(TM)): application to lipid-specific membrane protein topogenesis. Methods 36, 148-171. doi: 10.1016/j.ymeth.2004.11.002

Brown, J. R., Douady, C. J., Italia, M. J., Marshall, W. E., and Stanhope, M. J. (2001) Universal trees based on large combined protein sequence data sets. Nat. Genet. 28, 281-285. doi: 10.1038/90129

Cai, L., Liu, G., Rensing, C., and Wang, G. (2009). Genes involved in arsenic transformation and resistance associated with different levels of arsenic-contaminated soils. BMC Microbiol. 9:4. doi: 10.1186/14712180-9-4

Ciprandi, A., Baraúna, R. A., Santos, A. V., Gonçalves, E. C., Carepo, M. S. P., Schneider, M. P. C., et al. (2012). Proteomic response to arsenic stress in Chromobacterium violaceum. J. Integr. OMICS 2, 69-73. doi: 10.5584/jiomics.v2i1.84hh

Cserzö, M., Wallin, E., Simon, I., Von Heijne, G., and Elofsson, A. (1997). Prediction of transmembrane alpha-helices in prokaryotic membrane proteins: the dense alignment surface method. Protein Eng. 10, 673-676. doi: $10.1093 /$ protein/10.6.673

Dib, J., Motok, J., Zenoff, V. F., Ordoñez, O., and Farias, M. E. (2008). Occurrence of resistance to antibiotics, UV-B, and arsenic in bacteria isolated from extreme environments in high-altitude (above $4400 \mathrm{~m}$ ) andean wetlands. Curr. Microbiol. 56, 510-517. doi: 10.1007/s00284-008-9103-2

Dib, J., Weiss, A., Neumann, A., Ordoñez, O., Estevez, M. C., and Farías, M. E. (2009). Isolation of bacteria from remote high altitude Andean lakes able to grow in the presence of antibiotocs. Recent Pat. Antiinfect. Drug Discov. 4, 66-76. doi: 10.2174/157489109787236300

Escalante, G., Campos, V. L., Valenzuela, C., Yañez, J., Zaror, C., and Mondaca, M. A. (2009). Arsenic resistant bacteria isolated from arsenic contaminated river in 
the Atacama Desert (Chile). Bull. Environ. Contam. Toxicol. 83, 657-661. doi: 10.1007/s00128-009-9868-4

Escudero, L., Chong, G., Demergasso, C., Farias, M. E., Cabrol, N. A., Grin, E. A., et al. (2007). "Investigating microbial diversity and UV radiation impact at the high altitude lake Aguas Calientes, Chile," in Proceedings SPIE Conference on Instruments, Methods, and Missions for Astrobiology, Vol. 1, (San Diego, CA), 6694-6633.

Farías, M. E., Contreras, M., Rasuk, M. C., Kurth, D., Flores, M. R., Poiré, D. G., et al. (2014). Characterization of bacterial diversity associated with microbial mats, gypsum evaporites and carbonate microbialites in thalassic wetlands: Tebenquiche and La Brava, Salar de Atacama, Chile. Extremophiles 18, 311-329. doi: 10.1007/s00792-013-0617-6

Farias, M. E., Poire, D. G., Arrouy, M. J., and Albarracín, V. H. (2011). "Modern stromatolite ecosystems at alkaline and hipersalyne high-altitude lakes at the Argentinean Puna," in STROMATOLITES: Interaction of Microbes with Sediments Cellular Origin, Life in Extreme Habitats and Astrobiology, Vol. 18, eds J. Seckbach and V. Tewari (New York, NY: Springer), 427-441.

Farias, M. E., Rascovan, N., Toneatti, D. M., Albarracin, V. H., Flores, M. R., Poire, D. G., et al. (2013). The discovery of Stromatolites developing at $3570 \mathrm{~m}$ above sea level in a high-altitude volcanic lake Socompa, Argentinean Andes. PLoS ONE 8:E53497. doi: 10.1371/journal.pone.0053497

Fernandez Zenoff, V., Sineriz, F., and Farias, M. E. (2006). Diverse responses to UV-B radiation and repair mechanisms of bacteria isolated from highaltitude aquatic environments. Appl. Environ. Microbiol. 72, 7857-7863. doi: 10.1128/AEM.01333-06

Finn, R. D., Clements, J., and Eddy, S. R. (2011). HMMER web server: interactive sequence similarity searching. Nucleic Acids Res. 39, W29-W37. doi: 10.1093/nar/gkr367

Flores, M. R., Ordoñez, O. F., Maldonado, J., and Farías, M. E. (2009). Isolation of UV-B resistant bacteria from two high altitude Andean lakes $(4,400 \mathrm{~m})$ with saline and non saline conditions. J. Gen. Appl. Microbiol. 55, 447-458. doi: 10.2323 /jgam. 55.447

Fu, H. L., Meng, Y., Ordóñez, E., Villadangos, A. F., Bhattacharjee, H., Gil, J. A., et al. (2009). Properties of arsenite efflux permeases (Acr3) from Alkaliphilus metalliredigens and Corynebacterium glutamicum. J. Biol. Chem. 284, 19887-19895. doi: 10.1074/jbc.M109.011882

Haft, D. H., Loftus, B. J., Richardson, D. L., Yang, F., Eisen, J. A., Paulsen, I. T., et al. (2001). TIGRFAMs: a protein family resource for the functional identification of proteins. Nucleic Acids Res. 29, 41-43. doi: 10.1093/nar/29.1.41

Hrimpeng, K., Prapagdee, B., Banjerdkij, P., Vattanaviboon, P., Dubbs, J. M., and Mongkolsuk, S. (2006). Challenging Xanthomonas Campestris with low levels of arsenic mediates cross-protection against oxidant killing. FEMS Microbiol. Lett. 262, 121-127. doi: 10.1111/j.1574-6968.2006.00383.x

Hu, N. J., Iwata, S., Cameron, A. D., and Drew, D. (2011). Crystal structure of a bacterial homologue of the bile acid sodium symporter ASBT. Nature 478, 408-411. doi: $10.1038 /$ nature 10450

Jones, D. T. (1999). Protein secondary structure prediction based on position-specific scoring matrices. J. Mol. Biol. 292, 195-202. doi: 10.1006/jmbi.1999.3091

Krogh, A., Larsson, B., Von Heijne, G., and Sonnhammer, E. L. (2001). Predicting transmembrane protein topology with a hidden Markov model: application to complete genomes. J. Mol. Biol. 305, 567-580. doi: 10.1006/jmbi. 2000.4315

Lara, J., Escudero González, L., Ferrero, M., Chong Díaz, G., PedrósAlió, C., and Demergasso, C. (2012). Enrichment of arsenic transforming and resistant heterotrophic bacteria from sediments of two salt lakes in Northern Chile. Extremophiles 16, 523-538. doi: 10.1007/s00792-0120452-1

Larkin, M. A., Blackshields, G., Brown, N. P., Chenna, R., McGettigan, P. A., McWilliam, H., et al. (2007). Clustal W and Clustal X version 2.0. Bioinformatics 23, 2947-2948. doi: 10.1093/bioinformatics/btm404

Li, W., Jaroszewski, L., and Godzik, A. (2001). Clustering of highly homologous sequences to reduce the size of large protein databases. Bioinformatics 17, 282-283. doi: 10.1093/bioinformatics/17.3.282

Lopez, L., Pozo, C., Rodelas, B., Calvo, C., Juarez, B., Martinez-Toledo, M. V., et al. (2005). Identification of bacteria isolated from an oligotrophic lake with pesticide removal capacities. Ecotoxicology 14, 299-312. doi: 10.1007/s10646$003-6367-y$
López-Maury, L., Florencio, F. J., and Reyes, J. C. (2003). Arsenic sensing and resistance system in the Cyanobacterium Synechocystis sp. strain PCC 6803. J. Bacteriol. 185, 5363-5371. doi: 10.1128/JB.185.18.5363-5371.2003

Maciaszczyk-Dziubinska, E., Migocka, M., Wawrzycka, D., Markowska, K., and Wysocki, R. (2014). Multiple cysteine residues are necessary for sorting and transport activity of the arsenite permease Acr3p from Saccharomyces cerevisiae. Biochim. Biophys. Acta 1838, 747-755. doi: 10.1016/j.bbamem.2013.11.013

Maciaszczyk-Dziubinska, E., Migocka, M., and Wysocki, R. (2011). Acr3p is a plasma membrane antiporter that catalyzes $\mathrm{As}(\mathrm{Iii}) / \mathrm{H}(+)$ and $\mathrm{Sb}(\mathrm{Iii}) / \mathrm{H}(+)$ exchange in Saccharomyces Cerevisiae. Biochim. Biophys. Acta 1808, 1855-1859. doi: 10.1016/j.bbamem.2011.03.014

Macy, J. M., Santini, J. M., Pauling, B. V., O'neill, A. H., and Sly, L. I. (2000). Two new arsenate/sulfate-reducing bacteria: mechanisms of arsenate reduction. Arch. Microbiol. 173, 49-57. doi: 10.1007/s002030050007

Mansour, N. M., Sawhney, M., Tamang, D. G., Vogl, C., and Saier, M. H. Jr. (2007). The Bile/arsenite/riboflavin transporter (Bart) superfamily. FEBS J. 274, 612-629. doi: 10.1111/j.1742-4658.2006.05627.x

Mantelli, F., Scala, C., Ronchi, A., Gatti, A., and Minoia, C. (2003). Macrocostituenti ed elementi in traccia nelle acque dei laghi salini delle Andi de Catamarca e la Rioja (Argentina). Boll Chim Ig. 54, 37-44.

Okeke, B. C., Laymon, J., Oji, C., and Crenshaw, S. (2007). "Rapid bioreduction of hexavalent chromium in water by Exiguobacterium sp. GS1," in ASM General 107th Meeting (Toronto, ON: ASM Press), Q-199.

Ordoñez, O. F., Flores, M. R., Dib, J. R., Paz, A., and Farias, M. E. (2009). Extremophile culture collection from Andean lakes: extreme pristine environments that host a wide diversity of microorganisms with tolerance to UV radiation. Microb. Ecol. 58, 461-473. doi: 10.1007/s00248-009$9527-7$

Ordoñez, O. F., Lanzarotti, E., Kurth, D., Gorriti, M. F., Revale, S., Cortez, N., et al. (2013). Draft genome sequence of the polyextremophilic Exiguobacterium sp. strain S17, isolated from hyperarsenic lakes in the Argentinian Puna. Genome Announc. 1, pii: e00480-13. doi: 10.1128/genomeA.00480-13

Oremland, R. S., Stolz, J. F., and Hollibaugh, J. T. (2004). The microbial arsenic cycle in Mono Lake, California. FEMS Microb. Ecol. 48, 15-27. doi: 10.1016/j.femsec.2003.12.016

Overbeek, R., Fonstein, M., D'Souza, M., Pusch, G. D., and Maltsev, N. (1999). The use of gene clusters to infer functional coupling. Proc. Natl. Acad. Sci. U.S.A. 96, 2896-2901. doi: 10.1073/pnas.96.6.2896

Paez-Espino, D., Tamames, J., De Lorenzo, V., and Canovas, D. (2009). Microbial responses to environmental arsenic. Biometals 22, 117-130. doi 10.1007/s10534-008-9195-y

Pandey, S., Shrivastava, A. K., Singh, V. K., Rai, R., Singh, P. K., Rai, S., et al. (2012). A New arsenate reductase involved in arsenic detoxification in Anabaena Sp. Pcc7120. Funct. Integr. Genom. 13, 43-55. doi: 10.1007/s10142-012-0296-x

Pattanapipitpaisal, P., Mabbett, A. N., Finlay, J. A., Beswick, A. J., PatersonBeedle, M., Essa, A., et al. (2002). Reduction of $\mathrm{Cr}(\mathrm{VI})$ and bioaccumulation of chromium by Gram-positive and Gram-negative microorganisms not previously exposed to Cr-stress. Environ. Technol. 23, 731-745. doi: $10.1080 / 09593332308618367$

Poirel, J., Joulian, C., Leyval, C., and Billard, P. (2013). Arsenite-induced changes in abundance and expression of arsenite transporter and arsenite oxidase genes of a soil microbial community. Res. Microbiol. 164, 457-465. doi: 10.1016/j.resmic.2013.01.012

Pollastri, G., and McLysaght, A. (2005). Porter: a new, accurate server for protein secondary structure prediction. Bioinformatics 21, 1719-1720. doi: 10.1093/bioinformatics/bti203

Poptsova, M. S., and Gogarten, J. P. (2010). Using comparative genome analysis to identify problems in annotated microbial genomes. Microbiology 156, 1909-1917. doi: 10.1099/mic.0.033811-0

Qin, J., Rosen, B. P., Zhang, Y., Wang, G., Franke, S., and Rensing, C. (2006). Arsenic detoxification and evolution of trimethylarsine gas by a microbial arsenite S-adenosylmethionine methyltransferase. Proc. Natl. Acad. Sci. U.S.A. 103, 2075-2080. doi: 10.1073/pnas.0506836103

Rasuk, M. C., Kurth, D., Flores, M. R., Contreras, M., Novoa, F., Poiré, D. G., et al. (2014). Microbial characterization of microbial ecosystems associated to evaporites domes of gypsum in Salar de Llamara in Atacama desert. Microb. Ecol. 68, 483-494. doi: 10.1007/s00248-014-0431-4 
Ray, A., Lindahl, E., and Wallner, B. (2010). Model quality assessment for membrane proteins. Bioinformatics 26, 3067-3074. doi: 10.1093/bioinformatics/btq581

Richardson, E. J., and Watson, M. (2013). The automatic annotation of bacterial genomes. Brief. Bioinformatics 14, 1-12. doi: 10.1093/bib/bbs007

Rodrigues, D. F., and Tiedje, J. M. (2007). Multi-locus real-time pcr for quantitation of bacteria in the environment reveals Exiguobacterium to be prevalent in permafrost. FEMS Microb. Ecol. 59, 489-499. doi: 10.1111/j.15746941.2006.00233.x

Romero, L., Alonso, H., Campano, P., Fanfani, L., Cidu, R., Dadea, C., et al. (2003). Arsenic enrichment in waters and sediments of the Rio Loa (Second Region, Chile). Appl. Geochem. 18, 1399-1416. doi: 10.1016/S0883-2927(03) 00059-3

Rosen, B. P. (1999). Families of arsenic transporters. Trends Microbiol. 7, 207-212. doi: 10.1016/S0966-842X(99)01494-8

Rosen, B. P., Bhattacharjee, H., Zhou, T., and Walmsley, A. R. (1999). Mechanism of the ArsA ATPase. Biochim. Biophys. Acta 1461, 207-215. doi: 10.1016/S00052736(99)00159-5

Sacheti, P., Patil, R., Dube, A., Bhonsle, H., Thombre, D., Marathe, S., et al. (2014). Proteomics of arsenic stress in the gram-positive organism Exiguobacterium sp. PS NCIM 5463. Appl. Microbiol. Biotechnol. 98, 6761-6773. doi: 10.1007/s00253-014-5873-6

Saitou, N., and Nei, M. (1987). The neighbor-joining method: a new method for reconstructing phylogenetic trees. Mol. Biol. Evol. 4, 406-425.

Sali, A., and Blundell, T. L. (1993). Comparative protein modelling by satisfaction of spatial restraints. J. Mol. Biol. 234, 779-815. doi: 10.1006/jmbi. 1993.1626

Screpanti, E., and Hunte, C. (2007). Discontinuous membrane helices in transport proteins and their correlation with function. J. Struct. Biol. 159, 261-267. doi: 10.1016/j.jsb.2007.01.011

Seufferheld, M. J., Alvarez, H., and Farias, M. E. (2008). Role of polyphosphates in microbial adaptation to extreme environments. Appl. Environ. Microbiol. 74, 5867-5874. doi: 10.1128/AEM.00501-08

Silver, S., and Phung, L. T. (2005). Genes and enzymes involved in bacterial oxidation and reduction of inorganic arsenic. Appl. Environ. Microbiol. 71, 599-608. doi: 10.1128/AEM.71.2.599-608.2005

Stolz, J. F., and Oremland, R. S. (1999). Bacterial respiration of arsenic and selenium. FEMS Microbiol. Rev. 23, 615-627. doi: 10.1111/j.15746976.1999.tb00416.x

Suzek, B. E., Huang, H., McGarvey, P., Mazumder, R., and Wu, C. H. (2007). UniRef: comprehensive and non-redundant UniProt reference clusters. Bioinformatics 23, 1282-1288. doi: 10.1093/bioinformatics/btm098
Tamura, K., Peterson, D., Peterson, N., Stecher, G., Nei, M., and Kumar, S. (2011) Mega5: molecular evolutionary genetics analysis using maximum likelihood, evolutionary distance, and maximum parsimony methods. Mol. Biol. Evol. 28 2731-2739. doi: 10.1093/molbev/msr121

Thompson, C. C., Vicente, A. C., Souza, R. C., Vasconcelos, A. T., Vesth, T., Alves, N. J., et al. (2009). Genomic taxonomy of Vibrios. BMC Evol. Biol. 27:258. doi: 10.1186/1471-2148-9-258

Tusnády, G. E., and Simon, I. (2001). The HMMTOP transmembrane topology prediction server. Bioinformatics 17, 849-850. doi: 10.1093/bioinformatics/17.9.849

Valko, M., Morris, H., and Cronin, M. T. (2005). Metals toxicity and oxidative stress. Curr. Med. Chem. 12, 1161-1208. doi: 10.2174/0929867053764635

Villadangos, A. F., Fu, H. L., Gil, J. A., Messens, J., Rosen, B. P., and Mateos, L. M. (2012). Efflux permease CgAcr3-1 of Corynebacterium glutamicum is an arsenite-specific antiporter. J. Biol. Chem. 287, 723-735. doi: 10.1074/jbc.M111.263335

Vishnivetskaya, T. A., Kathariou, S., and Tiedje, J. M. (2009). The Exiguobacterium genus: biodiversity and biogeography. Extremophiles 13, 541-555. doi: 10.1007/s00792-009-0243-5

Vishnivetskaya, T. A., Petrova, M. A., Urbance, J., Ponder, M., Moyer, C. L., Gilichinsky, D. A., et al. (2006). Bacterial community in ancient siberian permafrost as characterized by culture and culture-independent methods. Astrobiology 6, 400-414. doi: 10.1089/ast.2006.6.400

Wysocki, R., Clemens, S., Augustyniak, D., Golik, P., Maciaszczyk, E., Tamas, M. J., et al. (2003). Metalloid tolerance based on phytochelatins is not functionally equivalent to the arsenite transporter Acr3p. Biochem. Biophys. Res. Commun. 304, 293-300. doi: 10.1016/S0006-291X(03)00584-9

Yin, X. X., Chen, J., Qin, J., Sun, G. X., Rosen, B. P., and Zhu, Y. G. (2011). Biotransformation and volatilization of arsenic by three photosynthetic cyanobacteria. Plant Physiol. 156, 1631-1638. doi: 10.1104/pp.111.178947

Conflict of Interest Statement: The authors declare that the research was conducted in the absence of any commercial or financial relationships that could be construed as a potential conflict of interest.

Copyright (C) 2015 Ordoñez, Lanzarotti, Kurth, Cortez, Farías and Turjanski. This is an open-access article distributed under the terms of the Creative Commons Attribution License (CC BY). The use, distribution or reproduction in other forums is permitted, provided the original author(s) or licensor are credited and that the original publication in this journal is cited, in accordance with accepted academic practice. No use, distribution or reproduction is permitted which does not comply with these terms. 